\title{
Contribuições da concepção de aprendizagem significativa de David Ausubel na formação de jovens aprendizes
}

\author{
Contributions of David Ausubel's concept of meaningful learning \\ in the formation of young apprentices
}

Marcelo Silva Oliveira Universidade Estadual de Goiás marceloadmsilva@hotmail.com

Marco Antônio de Carvalho Instituto Federal Goiano marco.carvalho@ifgoiano.edu.br

Sangelita Miranda Franco Mariano Instituto Federal Goiano sangelita.mariano@ifgoiano.edu.br

Resumo: O presente artigo tem como propósito refletir sobre as contribuições da concepção de Aprendizagem Significativa de David Ausubel (1982) para a formação de aprendizes. Objetiva analisar a constituição do processo de ensino e aprendizagem do Programa Jovem Aprendiz (PJA) a partir de práticas educativas influenciadas pelas múltiplas contradições que permeiam a ação educacional demarcada por um espaço-tempo histórico, social e cultural. Este estudo bibliográfico estrutura-se a partir de apontamentos iniciais sobre o PJA, aprendizagem e metodologia utilizada; discussão sobre aprendizagem significativa e prática educativa; caracterização do PJA e suas diretrizes bem como a interlocução entre estas e as alternativas pedagógicas formativas. Conclui-se que a aprendizagem significativa resulta de uma prática pedagógica, que auxilia a formação da jovem classe trabalhadora, pois alicerçada ao conhecimento prévio, na análise crítica e intencionalidades garante o sucesso das ações realizadas, impedindo que o ensino fique restrito à esfera da idealização e desconectado de sua objetivação.

Palavras-chaves: Aprendizagem Significativa. Jovem Aprendiz. Práticas Educativas.

Abstract: This article's purpose is to reflect on the contributions of David Ausubel's (1982) conception of Meaningful Learning to the formation of apprentices. It aims to analyze the constitution of the teaching and learning process of the Young Apprentice Program (PJA) based on educational practices influenced by the multiple contradictions that permeate the educational action demarcated by a historical, social and cultural space-time. This bibliographic study is structured from: initial notes on PJA, learning and methodology used; discussion of meaningful learning and educational practice; characterization of the PJA and its guidelines as well as the dialogue between these and educational training alternatives. It is concluded that the meaningful learning results from a pedagogical practice, which helps the formation of the young working class, because it is based on prior knowledge, in the critical analysis and intentions, it guarantees the success of the actions carried out, preventing the teaching from being restricted to the sphere of idealization and disconnected from its objectification.

Keywords: Meaninful Learning. Young Apprentices. Educational Practices. 


\section{Dialogia}

OLIVEIRA, Marcelo Silva; CARVALHO, Marco Antônio de; MARIANO, Sangelita Miranda Franco. Contribuições da concepção de aprendizagem significativa de David Ausubel na formação de jovens aprendizes

\section{Considerações iniciais}

A Lei $\mathrm{n}^{\circ}$ 10.097, de 19 de dezembro de 2000, conhecida popularmente como 'Lei da Aprendizagem', preconiza que organizações de médio e grande porte têm a obrigatoriedade de contratar jovens com idade entre 14 e 24 anos. O vínculo contratual poderá ser de até dois anos, período em que ele receberá uma capacitação ofertada pela empresa em parceria com a instituição formadora representante do Programa Jovem Aprendiz (PJA) naquela localidade (BRASIL, 2000).

A admissão de aprendizes é, acima de tudo, uma questão de responsabilidade social, empresarial e governamental. A formação dos novos talentos fomenta a economia ao criar postos de trabalho e promove a inclusão da nova geração na sociedade (WANTOWSKY, 2014). Devido a sua relevância, o poder público acompanha esse segmento de perto, bem como seus impactos sobre a criação de novos empregos.

Nesse sentido, existem diversas instituições atuando na formação de aprendizes, cada uma com uma metodologia de ensino personalizada. A proposta deste estudo não é questionar a validade ou eficácia dos processos de aprendizagem adotados por essas organizações. Pelo contrário, a intenção é proporcionar uma reflexão teórica, pautada pelos ensinamentos de Ausubel (1982), sobre possíveis alternativas pedagógicas que cooperem para a formação da juventude profissional.

A adoção de métodos de aprendizagem padronizados não são os mais eficazes. Para gerar melhores resultados, os fatores cognitivos e os conhecimentos prévios de qualquer estudante devem ser levados em consideração (KOCHHANN; MORAIS, 2014). Isso se torna ainda mais relevante para uma jovem classe trabalhadora, inserida em contexto de alta competitividade e instabilidade econômica.

Este estudo propõe uma reflexão teórica sobre possíveis contribuições da teoria de Aprendizagem Significativa de David Ausubel como alternativa pedagógica no processo de formação dos jovens aprendizes. Em outras palavras, analisaremos a constituição do processo de ensino e aprendizagem do Programa Jovem Aprendiz (PJA) a partir de práticas educativas. Para atender esse objetivo foi realizada uma pesquisa bibliográfica, destacando-se as seguintes obras: Novak (1981), Ausubel (1982), Moreira e Masini (1982), Moreira (2006), Orvalho e Alonso (2011), Behrens (2013), Kochhann e Morais (2014) e Filatro e Cavalcanti (2018).

A opção por este tipo de pesquisa justifica-se pela possibilidade de reflexão sobre uma determinada temática. Os procedimentos metodológicos devem seguir um padrão definido e não 
aleatório, ademais o objeto de estudo deve nortear as ações dos pesquisadores. A produção de conhecimento científico em temas poucos explorados pode ocasionar interpretações que servirão de base para o surgimento de outros projetos (LIMA; MIOTO, 2007).

Esse estudo possui natureza qualitativa, pois segundo Minayo (2001) se propõe a compreender um fenômeno e as suas relações no macro e microambiente. A interação dele com os objetivos da pesquisa, o diálogo com os teóricos que fundamentam o estudo desenvolvido e a busca por resultados que retratem com a maior veracidade possível a situação pesquisada.

O presente artigo está estruturado em três etapas. A primeira apresenta a definição de aprendizagem com significado pela perspectiva de Ausubel (1982), a segunda etapa traz diretrizes gerais sobre como é feita a capacitação de aprendizes e a última almeja associar os dois assuntos na tentativa de apresentar alternativas pedagógicas para a formação desses jovens.

\section{Aprendizagem Significativa de David P. Ausubel}

Há uma discussão sobre a necessidade de se repensar as práticas pedagógicas préestabelecidas do sistema de ensino. Um estudo meramente linear e sem interação com o aluno não atende às demandas da sociedade. A busca deve ser por uma educação holística ao invés de fragmentada, possibilitando ao estudante interagir e desenvolver o conteúdo dentro do contexto social em que esteja inserido (BEHRENS, 2013).

Para melhor compreensão da temática consideramos a necessidade de discutirmos as concepções de prática educativa numa perspectiva de qualidade socialmente referenciada que possa incluir a "todos e a cada um". Para tanto, é preciso considerar as características conjunturais e estruturais do contexto de desenvolvimento de tais práticas tendo em vista que esse campo é permeado por múltiplas dimensões que envolvem metodologia, relação professor e aluno e avaliação, bem como as concepções de ensino e aprendizagem que se traduzem em ações no espaço formativo. Veiga (2002) ressalta que a prática educativa também é uma práxis social com finalidades e propósitos determinados.

Nessa vertente, ao refletirmos sobre a prática educativa é imprescindível considerar os fatores sociais que a envolve, pois esta não se restringe apenas ao campo da sala de aula na qual é manifestada. Em concordância com tal abordagem Silva e Ramos (2006) asseveram que tal é uma prática social específica, de caráter histórico e cultural “[...] é ponto de partida para a teoria, mas que também se reformula a partir dela. Pressupõe uma análise e tomada de decisões em 


\section{Dialogia}

OLIVEIRA, Marcelo Silva; CARVALHO, Marco Antônio de; MARIANO, Sangelita Miranda Franco. Contribuições da concepção de aprendizagem significativa de David Ausubel na formação de jovens aprendizes

processo beneficiando-se do trabalho coletivo e da gestão democrática (SILVA; RAMOS, 2006, p. 2)".

Nesses termos, a prática educativa poderá ser caracterizada pelo conjunto de ações desenvolvidas com vista à aprendizagem a ao desenvolvimento dos estudantes. É, portanto, ação orientada por conhecimentos e objetivos organizados com o intuito de construir situações de ensino e aprendizagem que provoquem transformações dos sujeitos envolvidos no processo, bem como do próprio contexto de inserção e atuação desses alunos. Inferimos que sua finalidade está pautada na garantia de acesso dos sujeitos aos conhecimentos sociais e culturais acumulados ao longo da história da humanidade, por intermédio de um posicionamento crítico, reflexivo em meio a um cenário de criação, no decorrer da atuação de professores e alunos no meio social.

Sob esse olhar, Barbosa (2010) define a prática educativa como:

Dimensão da educação, cuja finalidade é historicamente determinada e abrange práticas formativas durante as quais ocorrem processos de socialização, transmissão, divulgação e apropriação de conhecimentos historicamente produzidos [...]. Consideram-se também as possibilidades de criação e transformação dos conhecimentos já existentes, à medida que a educação envolve sempre seres ativos e em condições de constituir outras formas e processos de agir, sentir pensar, representar (BARBOSA, 2010, p. 21).

Concebendo-a como uma prática social esta se configura como atividade teórico-prática a qual incorpora o prisma teórico e reflete a idealização de anseios presente na subjetividade humana (VEIGA, 2002). Em boa medida, podemos considerar a existência implícita de concepções e propósitos que implicam em escolhas que nortearão a organização do trabalho pedagógico exercido pelos professores, seja na seleção de metodologias, material didático, espaços educativos e avaliação. Todos esses elementos refletem a possibilidade de ampliação da aprendizagem dos alunos, tendo em vista a constituição de sujeitos com visão totalizante de mundo.

Nessa perspectiva, a teoria da Aprendizagem Significativa criada por David P. Ausubel apresenta-se como uma alternativa viável. O autor defende uma concepção de aprendizado que interaja com os conhecimentos prévios do acadêmico e possibilite reflexões, críticas e buscas por respostas. Essa metodologia preconiza que o ensino propiciará resultados duradouros, à medida que estabeleça conexões com a realidade social do estudante, caso contrário não terá significado para ele e será facilmente esquecido ou ignorado (AUSUBEL, 1982).

Novak (1981) preconiza que uma teoria de educacional não pode ser elaborada sem considerar que os seres humanos raciocinam, têm sentimentos e são capazes de agir. A relação 


\section{Dialogia}

OLIVEIRA, Marcelo Silva; CARVALHO, Marco Antônio de; MARIANO, Sangelita Miranda Franco. Contribuições da concepção de aprendizagem significativa de David Ausubel na formação de jovens aprendizes

entre docente e aluno envolve uma experiência afetiva bem como a troca de significados e sentimentos entre eles. Por isso o autor menciona que a teoria em análise é intelectualmente construtiva à medida que haja uma conexão entre as partes bem como uma predisposição a aprender.

Com os avanços tecnológicos, os quais podem ser notados em todas as camadas sociais, a comunicação é instantânea e muitas barreiras físicas deixaram de existir no mundo virtual. A produção de informação é feita em uma velocidade e quantidade que impossibilita a um único ser humano assimilar todo conteúdo. Logo, um aprendizado cartesiano e linear se torna ineficaz diante de um contexto social de contínuas mudanças, pensamento sistêmico e multidisciplinar (BEHRENS, 2013).

Nesse contexto, Kochhann e Morais (2014) veem a aprendizagem significativa de Ausubel (1982) como uma possibilidade pedagógica para uma educação mais integrada. Segundo as autoras, essa é uma teoria que pode ser trabalhada em todos os níveis de ensino, principalmente o infantil, fundamental e superior. É uma perspectiva inclusiva, o que permite sua incorporação em outros segmentos educacionais, corporativos e culturais.

Filatro e Cavalcanti (2018) destacam a tendência cognitivista da proposta de Ausubel (1982). Para os autores, ao buscar atribuir significado às novas informações armazenadas, essa vertente procura internalizar os novos conceitos seguindo uma linha de prioridades empíricas do usuário. Isso significa que o educador tem papel fundamental no processo de aprendizagem, pois uma de suas funções será identificar os conhecimentos prévios dos alunos e suas possíveis conexões com os temas que ele pretende trabalhar em sala de aula.

Moreira e Masini (1982) preconizam que a inclinação cognitiva é apenas um dos enfoques dessa metodologia, há outras duas: psicomotor (relacionado ao treino e prática) e o afetivo/emocional. Este tem como base as experiências vivenciadas pela pessoa, sejam elas positivas (alegres e prazerosas) ou negativas (dor, ansiedade e medo). Um exemplo simples e cotidiano é visto quando uma criança desobedece a uma orientação de seus pais, se prejudica de algum modo e internaliza que não pode repetir esse comportamento.

Essa linha de pensamento propõe uma mudança de paradigma:

O professor conservador, como "dono absoluto do saber", passa a ser um profissional que atua como orientador e parceiro na formação do educando e na produção de conhecimento. Nessa parceria, o professor submete à apreciação dos alunos seu projeto pedagógico, na busca de uma alienação e um processo de envolvimento e participação com os estudantes. Com a proposição de um trabalho coletivo, o docente torna o aluno corresponsável pela sua 
aprendizagem. Juntos, buscam caminhos compartilhados na investigação para a elaboração própria, relevante e significativa (BEHRENS, 2013, pp. 82-83).

O aprendizado significativo é visto como forma de reconstruir e expandir as ideias do indivíduo. Deve-se levar em consideração sua evolução cognitiva bem como as motivações para alguém frequentar a escola. Quanto maior a aproximação do educador da realidade social do estudante, maior a probabilidade de se conseguir bons resultados. Além disso, é necessário refletir sobre quais mecanismos são utilizados pela mente humana na tentativa de absorção de conteúdo e estruturação de conhecimento (AUSUBEL, 1982).

A aprendizagem significativa é caracterizada pela interação de uma nova informação a um elemento fundamental da estrutura cognitiva do indivíduo, ou seja, a informação é assimilada de modo significativo quando associado a outras ideias. Portanto, outros conceitos importantes e inclusivos que estejam na mente do sujeito acabam funcionando como âncoras. Desse modo, a aprendizagem significativa se consolida por atribuir significados a um conhecimento novo por interações não arbitrárias e substantivas (não literais) com significados evidentes, regulares e diferenciados, existentes a priori na estrutura cognitivo do estudante (NOVAK, 1981).

Ausubel (1982) considera essencial a interação entre uma nova informação e os conhecimentos prévios do estudante. Dentro da estrutura cognitiva constituída na mente do educando, os conceitos já internalizados são nominados pelo autor como subsunçores. Quando é feita uma conexão entre a nova informação que se pretende adquirir e o aprendizado prévio da pessoa, o novo conteúdo passa a ter significado. Sua assimilação assim como retenção e transformação dos subsunçores torna-se viável e compreensível.

Percebe-se que a aprendizagem significativa é caracterizada pela interação entre os conceitos que o indivíduo já é detentor e novas informações que são objeto de ensino em um determinado processo educativo. Entretanto Takeuchi (2009) alerta que os subsunçores podem ser entendidos apenas como os conhecimentos prévios relevantes para a pessoa.

O conhecimento prévio especificamente relevante é denominado subsunçor e funcionalmente serve como matriz ideacional e organizacional para a incorporação, compreensão e fixação do novo conhecimento na estrutura cognitiva de forma que o indivíduo passa a atribuir significado à nova informação (TAKEUCHI, 2009, p.17).

Os ensinamentos de Moreira (2006) relatam que o processo de aprendizagem pela ótica de Ausubel (1982) tem duas acepções: recepção ou descoberta. Na primeira, a informação é apresentada ao estudante, embora não se possa afirmar que seja um processo obrigatoriamente 
mecânico. Na segunda, o próprio aluno por meio de seus recursos e esforços a descobre. Ambas somente terão significado se estiverem ancoradas a um subsunçor existente.

Para que a aprendizagem dotada de significado ocorra, não há uma forma preestabelecida, o processo não deve ser mecânico. As novas informações serão eficazmente internalizadas por meio de uma metodologia interativa, dinâmica e relevante para o estudante (KOCHHANN; MORAES, 2014). Caso a assimilação dos novos conteúdos ocorra de maneira arbitrária ou por simples memorização, esse conhecimento será desprovido de significado, terá pouca aplicação prática e será rapidamente esquecido.

\section{Programa Jovem Aprendiz (PJA): percurso para a inserção social?}

O direito à profissionalização por parte dos jovens adquiriu status constitucional, sendo uma obrigação do Estado, da família e da sociedade:

Art. 227. É dever da família, da sociedade e do Estado assegurar à criança e ao adolescente, com absoluta prioridade, o direito à vida, à saúde, à alimentação, à educação, ao lazer, à profissionalização, à cultura, à dignidade, ao respeito, à liberdade e à convivência familiar e comunitária, além de colocá-los a salvo de toda forma de negligência, discriminação, exploração, violência, crueldade e opressão (BRASIL, 1988).

Com o advento da Lei n 10.097 , de 19 de dezembro de 2000, a inserção dos jovens no mundo do trabalho foi regulamentada. O diploma legal estabelece as diretrizes gerais de atuação dos programas de aprendizagem, os quais serão responsáveis por uma formação técnicoprofissional compatível com o desenvolvimento físico, moral e psicológico dos aprendizes (BRASIL, 2000).

Esse dispositivo legitimou os direitos à educação profissional e à proteção no trabalho, apresentados pelo Estatuto da Criança e do Adolescente (ECA). Criado praticamente uma década antes da 'Lei da Aprendizagem', o normativo tem como um dos principais os objetivos o combate e erradicação do trabalho infantil bem como a garantia ao labor a partir dos 16 anos, salvo na condição juvenil. Para isso preconiza que a formação do jovem deve prepará-lo para o mundo do trabalho e mantê-lo frequentando regularmente a escola (BRASIL, 1990).

Posteriormente, com a finalidade de regulamentar a legislação pertinente, foi editado o Decreto $n^{\circ} 5.598$, de $1^{\circ}$ de Dezembro de 2005. Esse ato especificou as diretrizes do contrato de aprendizagem e a obrigatoriedade dos estabelecimentos destinarem de cinco até quinze por cento 
de suas vagas para aprendizes. Além disso, dispensaram-se dessa exigência as microempresas e as empresas de pequeno porte, bem como as entidades sem fins lucrativos cujo objeto de atuação seja educação profissional (BRASIL, 2005).

Todavia, com a entrada em vigor do Decreto n 9.579, de 22 de Novembro de 2018, houve a revogação das diretrizes contidas no antigo Decreto nº5.598. A atual regulamentação estabeleceu novas condutas sobre o direito à profissionalização, capacitação, entidades qualificadas, obrigatoriedade de contratação, espécies de contrato, direitos trabalhistas, jornada de trabalho, remuneração, entre outros temas foram esmiuçados nesse ato normativo.

Para o Decreto 9.579/2018 a formação técnico-profissional metódica será de incumbência dos serviços nacionais de aprendizagem, como é o caso de Senai, Senar, Senac, etc. Organizações sem fins lucrativos envolvidas com a educação profissional de jovens e escolas técnicas e agrotécnicas (atuais Institutos Federais de Educação, Ciência e Tecnologia) também são consideradas aptas. Primando pela qualidade dessa formação, deverá ser criado um cadastro nacional dessas entidades, com o objetivo de avaliar a compatibilidade do conteúdo e a duração do programa (BRASIL, 2018).

Outro aspecto fundamental é o estabelecimento de um relacionamento próximo com a empresa contratante, a escola e a família do aprendiz. Essa aproximação torna-se necessária para combater a evasão escolar e acompanhar o desempenho profissional do jovem. Parte desse monitoramento consiste em:

[...] estabelecimento deve designar formalmente um monitor que ficará responsável ficará responsável pela coordenação e acompanhamento das atividades práticas do aprendiz, buscando garantir uma formação que possa contribuir para o seu desenvolvimento integral e a consonância com os conteúdos estabelecidos no curso em que foi matriculado, de acordo com o programa de aprendizagem (MANUAL DA APRENDIZAGEM PROFISSIONAL, 2019, p. 48).

De acordo com o Manual da Aprendizagem Profissional (2019), amplamente divulgado junto às empresas, o Programa Nacional de Aprendizagem, do qual podem participar jovens adolescentes e adultos, consiste em instrumento com considerável relevância no que diz respeito à oportunidade de inclusão econômica e social. O documento destaca que ao mesmo tempo em que proporciona aos jovens uma formação que embasará sua vida profissional futura, permite às empresas capacitarem mão de obra de acordo com suas necessidades e exigências, em meio a um cenário notadamente subordinado às tecnológicas. 
Apesar de as empresas terem um papel fundamental na formação do aprendiz, sua atuação isolada não é suficiente para o cumprimento eficaz dos objetivos preconizados pela lei. Por abranger um elevado número de jovens em situação de vulnerabilidade social, a inserção no mercado de trabalho é uma responsabilidade a ser compartilhada entre pais, organizações privadas, instituições de qualificação e o setor público. Com a correta condução desse processo, almeja-se transformar a realidade de muitos adolescentes, principalmente os de baixa-renda.

Rizzo e Chamon (2011) destacam que o trabalho tem um significado particular e de grande importância para os jovens. Possibilita construir uma carreira, melhorar sua autoestima, ter autonomia, gerar um senso de responsabilidade e conquistar sua independência financeira ou, na maioria das vezes, complementar a renda familiar. A sociedade atual valoriza um emprego não apenas pelo salário ao final de cada mês, mas também pelas suas recompensas morais e psicológicas.

\subsection{Diretrizes pedagógicas dos programas de aprendizagem}

No âmbito da dimensão formativa, a aprendizagem profissional consiste em instrumento de qualificação profissional para jovens aprendizes. Realizada via regulamentação legal, impõe o cumprimento de cota de contratação por parte das empresas, as quais se responsabilizam por assegurar formação técnico-profissional desenvolvida por meio de atividades de cunho teórico e prático (BRASIL, 2000).

O planejamento e coordenação dessas ações resultarão em programas, os quais serão ofertados por entidades habilitadas para esse fim. Essas instituições devem buscar não apenas o desenvolvimento de competências profissionais, mas também ações que valorizem a educação, incentivem o senso de coletividade, promovam a inserção social e fomentem a cidadania (MANUAL DA APRENDIZAGEM PROFISSIONAL, 2019).

Uma das metodologias de ensino que vem sendo adotada para a formação profissional de jovens é a Estrutura Modular. A matriz curricular dos programas é elaborada em módulos, contendo objetivos específicos e duração variáveis. O conteúdo apresentado, os materiais fornecidos, a organização do espaço escolar, o trabalho em grupo bem como sua composição e as interações entre os envolvidos formam unidades significativas de aprendizagem, (ORVALHO; ALONSO, 2011).

Os projetos pedagógicos de cada instituição trabalham atividades diversas, a depender de seu segmento e foco de atuação, contudo há uma preocupação em interligar os componentes 


\section{Dialogia}

OLIVEIRA, Marcelo Silva; CARVALHO, Marco Antônio de; MARIANO, Sangelita Miranda Franco. Contribuições da concepção de aprendizagem significativa de David Ausubel na formação de jovens aprendizes

curriculares. Essa postura está de acordo com o pensamento de Roldão (2009), a autora menciona que a mera apresentação de variados conhecimentos não é suficiente por si só para um aprendizado duradouro e de qualidade.

É imperioso ressaltar que Aprendizagem Significativa não consiste necessariamente em conteúdo significativo, os conteúdos e os instrumentos utilizados na prática educativa podem ou não ser relevantes ou expressivos para os aprendizes. Isso dependerá de suas estruturas cognitivas e das experiências que constituem as singularidades de cada sujeito, imprimindo um modo próprio de perceber e representar os objetos (AUSUBEL, 1982).

Depreendemos que o ensino centrado na provocação de respostas não é por si gerador de aprendizagens. Todavia, novos conhecimentos se somam à organização cognitiva dos jovens à medida que os conteúdos e atividades (a partir da práxis) se caracterizam como ação intencional, reflexiva e questionadora. Nesse sentido, a formação para além da dimensão técnica e quantitativa exige unidades de aprendizagens planejadas e executadas de modo a responder metodologicamente as demandas e limites de uma educação inclusiva, resultando em prática educativa problematizadora, consciente, coletiva e capaz de oportunizar aos aprendizes a ampliação de seus conhecimentos em relação aos temas propostos.

\section{Aprendizagem Significativa na formação de aprendizes}

As entidades responsáveis pela formação de aprendizes procuram trabalhar de modo dinâmico e interativo com seus alunos. Essa postura vai ao encontro das características que envolvem a aprendizagem significativa de Ausubel (1982). Moreira (2006) descreve tal ensino como não literal, ou seja, não se trata de uma simples memorização, mas um verdadeiro aprendizado do conteúdo e a possibilidade de transmiti-lo a terceiros.

A perspectiva formativa dos programas de aprendizagem profissional traz a exigência de um intercâmbio entre a empresa (responsável pelo o contrato de trabalho) e a instituição formadora. Desse modo, espera-se que a dimensão formativa sobressaia a uma mera preparação voltada para o setor produtivo, pois não basta que os estabelecimentos cumpram a obrigatoriedade legal de empregar e matricular nos cursos de aprendizagem 5\%, no mínimo, e 15\%, no máximo, da força de trabalhado existente na instituição (MANUAL DA APRENDIZAGEM PROFISSIONAL, 2019).

De acordo com Franco (2016) as ações nas instituições educacionais formais ou informais se realizam com o intuito de organizar e potencializar as intencionalidades de um determinado 
projeto educativo. Argumenta-se a favor de uma epistemologia crítico-emancipatória, que considera a ação pedagógica uma prática social conduzida por um pensamento reflexivo e que contribua com a formação de educandos em sua plenitude.

A grande diferença é a perspectiva de ser crítica e não normativa; de ser práxis e não treinamento; de ser dialética e não linear. Nessa perspectiva, as práticas pedagógicas realizam-se como sustentáculos à prática docente, num diálogo contínuo entre os sujeitos e suas circunstâncias, e não como armaduras à prática, que fariam com que esta perdesse sua capacidade de construção de sujeitos (FRANCO, 2016, p. 538).

Apesar da relevância desta concepção educacional, sua aplicação pode ser vista como um desafio para uma juventude profissional que tende a trabalhar de maneira precoce para auxiliar no sustento familiar. A necessidade de complementar a renda auferida pelos pais é a realidade de muitos adolescentes. Nessa temática, há intenso debate sobre os possíveis fatores e justificativas para esse movimento, por exemplo:

Existe no país uma cultura que valoriza o trabalho precoce em alguns contextos como forma de prevenir crianças e adolescentes de possíveis desvios das normas sociais, como a entrada na criminalidade, por exemplo. Existem ainda fatores que dizem respeito à estruturação econômica da família, pois a entrada do jovem no mundo do trabalho pode auxiliar, por exemplo, na manutenção de gastos com alimentação, moradia e educação (FRENZEL; BARGAGI, 2014, p. $80)$.

Nesse contexto, a materialização do processo de ensino coaduna com a Aprendizagem Significativa na medida em que sua execução tem demonstrado contribuições para a progressão da escolaridade formal e o direito à formação técnico-profissional. Destaca-se a formação voltada às tecnologias de informação e comunicação (TIC), bem como os conhecimentos relativos habilidades específicas de uma ou mais ocupações que “[...] possuem base técnica próxima e características complementares, garantindo uma formação que amplie as possibilidades de inserção do aprendiz no mercado trabalho ao término do programa" (MANUAL de APRENDIZAGEM PROSSIONAL, 2019, p. 11).

Os processos educativos, em maior ou menor intensidade, são permeados por contradições relativas à aprendizagem que produzem. Portanto, o termo aprendizado em sentido amplo decorre de sínteses interpretativas, a partir de relações dialéticas construídas entre o sujeito, meio e objeto do conhecimento. Não se pressupõe ação iminente e totalmente previsível, pois depende diretamente da "[...] interpretação do sujeito, dos sentidos criados, das circunstâncias atuais e antigas. Enfim, não há correlação direta entre ensino e aprendizagem. Quase que se pode dizer que as aprendizagens ocorrem sempre para além, ou para aquém do 


\section{Dialogia}

OLIVEIRA, Marcelo Silva; CARVALHO, Marco Antônio de; MARIANO, Sangelita Miranda Franco. Contribuições da concepção de aprendizagem significativa de David Ausubel na formação de jovens aprendizes

planejado; ocorrem nos caminhos tortuosos, lentos, dinâmicos das trajetórias dos sujeitos" (FRANCO, 2016, p. 604).

A prática educativa ocorre em estreita relação com os enfoques pluridimensionais da realidade local, e a construção histórica dos sujeitos individuais e coletivos subjacentes aos processos formativos. No que concerne aos professores estes estão submetidos a uma "[...] fiscalização e subordinação da entidade formadora para garantir a qualidade e a eficiência da educação dos jovens e adolescentes. buscando a melhor qualificação humana e profissional de seus adolescentes e jovens aprendizes" (MANUAL de APRENDIZAGEM PROFISSIONAL, 2019, p. 38).

A compreensão acerca da Aprendizagem Significativa perpassa pelo entendimento sobre a aquisição e a utilização de conceitos na prática educativa. A aprendizagem decorre de movimentos assimilativos de novos conceitos e proposições associadas às ideias preexistentes já internalizados pelo sujeito (AUSUBEL, 1982). Esses conceitos estruturam-se em situações de reflexão e pensamento autônomo sobre questões acerca das experiências cotidianas e do conhecimento sistematizado.

Desse modo, o processo formativo do jovem aprendiz deve partir do uso competente dos recursos cognitivos para estruturar os saberes e as experiências por intermédio de memorização, comparação, associação, classificação e interpretação. O objetivo é compreender, analisar e intervir nos fenômenos concernentes ao mundo do trabalho, bem como estabelecer conexões entre eles e o contexto social em que esta juventude está inserida.

A formação do Programa Jovem Aprendiz tende a caminhar nessa direção ao apregoar que a capacitação deverá ser realizada por meio de atividades teóricas e práticas, as quais terão seu grau de complexidade aumentado de maneira progressiva, a fim de desenvolver uma formação profissional de nível básico que possibilite desdobramento de ações conjuntas entre trabalho e aprendizagem em um mesmo contexto de ação (MANUAL DA APRENDIZAGEM PROFISSIONAL, 2019). Além disso, será delimitado um horário especial para as atividades de modo que o curso não prejudique a frequência escolar, a qual é obrigatória (BRASIL, 2018).

Ausubel, Novak e Hanesian (1980) discorrem sobre o uso de organizadores prévios. Estes representam materiais ancoradouros para o novo conhecimento ser mobilizado como estratégia pedagógica para o desenvolvimento de conceitos subsunçores que contribuam para aprendizagens posteriores. Em face dessa consideração, Moreira (2006, p. 2) define como 
objetivo do organizador prévio “[...] servir de ponte entre o que aprendiz já sabe e o que ele deveria saber, a fim de que o novo material pudesse ser aprendido de forma significativa".

Os organizadores prévios são reconhecidos como conteúdos introdutórios que permitem o estabelecimento de relações, ideias, proposições e conceitos já presentes na estrutura cognitiva do aluno com aqueles incluídos no material a ser estudado. Os organizadores prévios, contudo não são apenas exposições introdutórias. Para Moreira (2006), eles têm a função de identificar o conteúdo relevante na estrutura cognitiva e explicar a relevância desse conteúdo para a aprendizagem do novo material.

Na prática educativa dos jovens aprendizes, o educador deve ter clareza com relação aos conhecimentos e saberes que os estudantes já possuem. Além de fornecer uma visão geral do material a ser trabalhado, os objetivos previamente propostos e relações que podem ser estabelecidas. O intuito será construir organizadores que possam integrar e diferenciar as novas informações, conceitos, ideias ou proposições já consolidadas em sua estrutura cognitiva.

\section{Considerações finais}

Esta reflexão é puramente teórica e não foi realizada nenhuma atividade prática, contudo a revisão da literatura indica que não existem impedimentos para futuras tentativas. A retenção do conhecimento aumenta à medida que o estudante se identifica com determinado conteúdo. Como os aprendizes estão sendo preparados para o mundo do trabalho, infere-se que eles almejam se apropriar daquele conhecimento e o valorizam.

Os jovens estão inseridos em um contexto de contínuas e intensas transformações, não podem ser considerados meros receptores de conteúdo. Ausubel (1982) afirma que quando um novo conhecimento interage de forma significativa com a estrutura cognitiva existente, ele a altera de modo que haja uma aquisição de novas informações e a retenção das anteriores. $\mathrm{O}$ estudante verá a associação com sua realidade e dará sentido àquele conteúdo.

Falar em aprendizagem significativa está longe de ser uma ciência exata, cada indivíduo é único em sua maneira de ver, agir e sentir. Contudo, buscar alternativas pedagógicas para auxiliar na formação da jovem classe trabalhadora não parece ser uma reflexão inócua. Orientar pessoas é um grande desafio, não existe uma fórmula pronta, porém comprometimento, metas claras, dedicação e flexibilidade para receber novas ideias tende a ser um bom começo.

Ao consideramos a natureza da Aprendizagem Significativa, destacamos sua relevância para os programas de aprendizagem profissional. Os documentos oficiais e a literatura a respeito 


\section{Dialogia}

OLIVEIRA, Marcelo Silva; CARVALHO, Marco Antônio de; MARIANO, Sangelita Miranda Franco. Contribuições da concepção de aprendizagem significativa de David Ausubel na formação de jovens aprendizes

sustentam a possibilidade de uma prática educativa comprometida com a ampliação das habilidades cognitivas desses educandos e a consequente formação da jovem classe trabalhadora alicerçada no conhecimento prévio, na análise crítica e sustentabilidade do processo formativo.

\section{Referências}

AUSUBEL. D. P. A aprendizagem significativa: a teoria de David Ausubel. São Paulo: Moraes, 1982.

AUSUBEL, D. P., NOVAK, J. D., HANESIAN, H. Psicologia educacional. Tradução Eva Nick. Rio de Janeiro: Interamericana, 1980.

BARBOSA, I. G. Prática Pedagógica na educação infantil. In: OLIVEIRA. D. A.; DUARTE, A. C.; VIEIRA, L. F. Dicionário: trabalho, profissão e condição docente. Belo Horizonte: Faculdade de Educação, UFMG, 2010.

BEHRENS, M. A. O paradigma emergente e a prática pedagógica. Petrópolis: Vozes, 2013.

BRASIL. Constituição da República Federativa do Brasil de 1988. Diário Oficial da República Federativa do Brasil, Brasília-DF. Disponível em:

<http://www.planalto.gov.br/ccivil_03/constituicao/constituicao.htm>. Acesso em: 10 dez. 2019.

BRASIL. Lei Ordinária no 8.069, de 13 de julho de 1990. Estatuto da Criança e do Adolescente. Diário Oficial da República Federativa do Brasil, Brasília-DF. Disponível em: <http://www.planalto.gov.br/ccivil_03/leis/18069.htm>. Acesso em: 10 dez. 2019.

BRASIL. Lei Ordinária no 10.097, de 19 de dezembro de 2000. Lei Nacional da Aprendizagem. Diário Oficial da República Federativa do Brasil, Brasília-DF. Disponível em: <http://www.planalto.gov.br/ccivil_03/leis/110097.htm>. Acesso em: 19 nov. 2019.

BRASIL. Decreto ${ }^{\circ} 5.598$ de 1 de Dezembro de 2005. Regulamenta a contratação de aprendizes e dá outras providências. Diário Oficial da República Federativa do Brasil, Brasília-DF. Disponível em: <http://www.planalto.gov.br/ccivil_03/_ato20042006/2005/decreto/d5598.htm>. Acesso em: 20 nov. 2019.

BRASIL. Decreto n ${ }^{\circ} 9.579$ de 22 de Novembro de 2018. Regulamenta a contratação de aprendizes e dá outras providências. Diário Oficial da República Federativa do Brasil, Brasília-DF. Disponível em: <http://www.planalto.gov.br/ccivil_03/_ato2015-

2018/2018/decreto/D9579.htm>. Acesso em: 22 nov. 2019.

FILATRO, A; CAVALCANTI, C. C. Metodologias Inov-ativas na educação presencial, a distância e corporativa. Disponível em: [Minha Biblioteca]. $<$ https://integrada.minhabiblioteca.com.br/\#/books/9788553131334/>. Acesso em: 10 jan. 2020. 
FRANCO, M. A. S. Prática pedagógica e docência: um olhar a partir da epistemologia do conceito. RBEP, Brasília, v. 97, n. 247, p. 534-551, set./dez. 2016.

FRENZEL, H. S.; BARDAGI, M. P. Adolescentes Trabalhadores Brasileiros: um breve estudo bibliométrico. Psicologia, Organizações e Trabalho. Florianópolis, v. 14, n. 1, p. 79-88, 2014.

KOCHHANN, A.; MORAES, A. C. Aprendizagem Significativa na perspectiva de David Ausubel. Anápolis: Editora UEG, 2014.

LIMA, T. C. S.; MIOTO, R. C. T. Procedimentos metodológicos na construção do conhecimento científico: a pesquisa bibliográfica. Katálysis. Florianópolis, v. 10 n. esp. p. 37-45, mar/abr. 2007.

MANUAL DA APRENDIZAGEM PROFISSIONAL. O que é preciso saber para contratar o aprendiz. Brasília: SINAIT, 2019.

MINAYO, M.C.S. Pesquisa social: teoria, método e criatividade. 19. ed. Petrópolis: Vozes, 2001.

MOREIRA, M.A. A teoria da aprendizagem significativa e sua implementação em sala de aula. Brasília: Editora UNB, 2006.

MOREIRA, M. A.; MASINI, E. F. S. Aprendizagem significativa: a teoria de David Ausubel. São Paulo: Moraes, 1982.

NOVAK, J. D. Uma teoria de educação. São Paulo: Pioneira, 1981.

OLIVEIRA, M. M. Como fazer pesquisa qualitativa. Petrópolis: Vozes, 2007.

ORVALHO, L.; ALONSO, L. A estrutura modular nos cursos profissionais das escolas secundárias públicas: do modelo curricular às práticas. Uma investigação colaborativa. Revista Portuguesa de Investigação Educacional, Porto, v. 10, p. 79-121, fev/2011.

RIZZO, C. B. S.; CHAMON, E. M. O sentido do trabalho para o adolescente. Educação \& Saúde, Rio de Janeiro, v. 8 n. 3, p. 407-417, nov/fev. 2011.

ROLDÃO, M. C. Estratégias de ensino. O saber e o agir do professor. Vila Nova de Gaia, PT: Fundação Manuel Leão, 2009.

SILVA, J.; RAMOS, M. M. Prática Pedagógica numa perspectiva interdisciplinar. Disponível em: < https://docplayer.com.br/277398-Pratica-pedagogica-numa-perspectivainterdisciplinar.html>. Acesso em: 20 jan. 2020.

TAKEUCHI, M. Y. Estudo do uso de mapa conceitual na promoção de aprendizagem significativa de conteúdo de neurociência na graduação. (Dissertação de Mestrado). Universidade de São Paulo, Brasil, 2009.

VEIGA. I. P. A. A prática pedagógica do professor de didática. Campinas, Papirus, 2002. 


\section{Dialogia}

OLIVEIRA, Marcelo Silva; CARVALHO, Marco Antônio de; MARIANO, Sangelita Miranda Franco. Contribuições da concepção de aprendizagem significativa de David Ausubel na formação de jovens aprendizes

WANTOWSKY, G. Trabalho do menor aprendiz é também uma questão de responsabilidade social. Boletim Jurídico, Uberaba-MG, v. 3, n. 99. Disponível em:

<http://www.boletimjuridico.com.br/ doutrina/texto.asp?id=384> Acesso em: 25fev.2020.

Recebido em: 28 fev. 2020 / Aprovado em: 18 mar. 2020

Cite como (ABNT NBR 6023:2018)

OLIVEIRA, Marcelo Silva; CARVALHO, Marco Antônio de; MARIANO, Sangelita Miranda Franco. Contribuições da concepção de aprendizagem significativa de David Ausubel na formação de jovens aprendizes. Dialogia, São Paulo, n. 34, p. 34-49, jan./abr. 2020. Disponível em: https://doi.org/10.5585/Dialogia.N34.16704. 